\title{
KAJIAN LITERATUR SIMULASI PENGARUH PENERAPAN UNDERPASS DI PERSIMPANGAN KENTUNGAN YOGYAKARTA TERHADAP BEBERAPA PERSIMPANGAN LAINNYA
}

\author{
Adyk Marga Raharja, I Gusti Bagus Budi Dharma \\ Jurusan Teknik Industri, Fakultas Teknik, Universitas Gadjah Mada \\ Jl.Grafika No.2 Yogyakarta, 55281 \\ Telp. (0274) - 521673 \\ Email : adyk.marga.r@mail.ugm.ac.id
}

\begin{abstract}
The intersection of Kentungan is one of the intersections that connects North Ringroad Road and Kaliurang Street which looks increasingly stuck in Yogyakarta. This is due to an uneven increase in vehicle vehicles to road infrastructure. The peak of traffic jam at Intersection of Junction often occurs at 16.00-17.30 WIB. The problem at this junction is the amount of time delay and the length of the queue. One way to reduce congestion problems at the Intersection is to construct road infrastructure, one underpass. Based on these problems, research on the effect of underpass application on congestion parameters at several other intersections adjacent to the intersection of Kentungan. This research is a Multi Channel Multi Phase model configuration, by creating an underpass model of the Autodesk Infraworks 360 software. Before modeling underpass conditions, it is done in advance of the existing model of Intersection of Kentungan. The data inputted to this existing model is the total data of vehicles crossing the intersection of Kentungan for one hour. Verification model in this research is done by visual testing and check the duration of green light at the time of simulation done. Validation in this research is done by using hypothesis test, paired t-test. Then the parameters for validation are data ie the average waiting time of the vehicle, the maximum queue length and the number of vehicles passing through the green light in one cycle.In this study using two scenarios, in scenario 1 is the underpass model with the condition of the intersection and the scenario 2 is the underpass model with the roundabout condition. The results obtained from both scenarios are compared with the existing model results. The compared parameters are the average vehicle delay time and maximum queue length on each approach. It is expected from the comparison analysis to show that the Kentungan Intersection after the built underpass has decreased significantly on the average delay time and maximum queue length.
\end{abstract}

Keywords: Kentungan street intersection,Autodesk Infraworks 360, waiting time, delay, queue length.

1. Pendahuluan

Daerah Istimewa Yogyakarta adalah

salah satu provinsi yang memiliki pertumbuhan penduduk yang cenderung semakin meningkat. DIY memiliki luas wilayah $3.185,8 \mathrm{~km}^{2}$ yang terbagi menjadi lima wilayah, yaitu Kota Yogyakarta, Bantul, Sleman, Kulonprogo dan Gunungkidul. DIY selama ini dikenal masyarakat sebagai kota pelajar, kota budaya dan kota tujuan wisata, sehingga secara langsung dapat mengakibatkan penambahan jumlah penduduk, baik yang dikarenakan penduduk asli maupun penduduk pendatang. selain itu juga memicu pertumbuhan sarana pendukung, seperti pusat perbelanjaan, perhotelan, pusat bisnis dan perkantoran, serta pusat pendidikan.

Seiring pertambahan jumlah penduduk maka kemacetan didalam suatu kota semakin besar pula. Salah satu penyebab kemacetan tersebut adalah peningkatan jumlah kendaraan di Provinsi Daerah Istimewa Yogyakarta (DIY). Hal ini terbukti dari data terbaru Ditlantas (Direktorat Lalu Lintas) Polda DIY yang 
diterima Tribun Jogja (Handito, 2016), bahwa sampai tanggal 28 September 2016 ada 84.312 kendaraan bermotor baru di DIY. Dari data tesebut, ada 71.566 kendaraan roda dua (sepeda motor) baru dan 12.746 kendaraan roda empat (mobil) baru..

Menurut data dari Pembangunan Jembatan dan Jalan Bidang Bina Marga DPUP-ESDM DIY dalam mengurangi kemacetan di Persimpangan tersebut, salah satu solusi yang dapat dilakukan adalah melakukan pembangunan infrastruktur. Berdasarkan feasibility study yang telah dilakukan di kawasan tersebut, hasilnya sudah layak untuk dibangun infrastruktur, baik underpass maupun flyover. Berdasarkan Detail Engineering Design (DED), hasilnya ke arah underpass untuk mengurangi kemacetan khususnya di Persimpangan Kentungan Jalan Kaliurang. (Sunartono, 2016).

\subsection{Simulasi}

Simulasi adalah suatu proses yang menyerupai suatu sistem nyata, sehingga dapat menyelesaikan permasalahanpermasalahan yang ada. Namun proses simulasi adalah proses yang melakukan perulangan, sehingga memiliki kemungkinan terjadinya kesalahan. Menurut Law dan Kelton (1991) keuntungan dari simulasi diantaranya: Dapat menyelesaikan masalah kompleks yang relatif sulit untuk diselesaikan dengan cara analisis, Mempermudah dalam mengevaluasi kerja suatu sistem sebagai reaksi terhadap adanya sekumpulan masukan dan Mempermudah mengamati suatu sistem yang secara teknik sulit diamati karena masalah waktu.

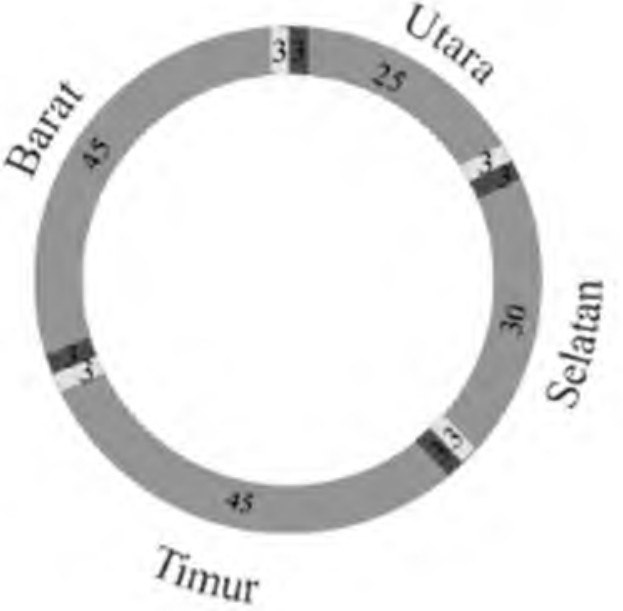

Gambarl Siklus Lampu Lalu Lintas Aktual

Selain memberikan keuntungan, simulasi juga memiliki beberapa kekurangan (Banks et al., 2000) diantaranya:Memerlukan pelatihan yang khusus untuk dapat membuat suatu model. Kualitas suatu analisis tergantung dari kualitas model dan keahlian pemodel serta hasil simulasi seringkali susah dijelaskan dan diinformasikan. Hal ini dikarenakan karena input model simulasi bersifat random sistem nyata.

Penelitian tentang simulasi lalu lintas telah banyak dilakukan di negaranegara lain khususnya Asiadan negara Eropa lainnya. Menurut Kamrani, et al (2014), Parameter yang ditinjaudari simulasi lalu lintas di Jalan Universiti, Kota Skudai, Johor Malasyia adalah waktu tunggu dan panjang antrian. Sedangkan untuk validasi dilakukan dengan menghitung percentage error dari rata-rata waktu tunggu antara hasil simulasi dan kondisiaktual. Penelitian yang dilakukan oleh Shen(2011), melakukan manajemen sistem lalu lintas dengan penentuan waktu siklus dari persimpangan. Pada penelitian ini dilakukan pembuatan model multi-agent system untuk kasus 4 persimpangan dengan metode algoritma genetik, dengan tujuan yang ingin dicapai yaitu memaksimalkan jumlah kendaraan yang melintasi 4 persimpangan tersebut dalam periode waktu tertentu. Graphics processing unit diaplikasikan sebagai parallel computing dari hasil simulasi dan optimasi yang telah dilakukan. Penggunaan GPU memberikan 
hasil yang lebih cepat jika dibandingkan dengan implementasi CPU.

Penelitian lainnya dilakukan oleh Salvo, et al (2014), menggunakan Unmanned Aerial Vehicle (UAV) untuk mengambil data berupa video yang merekam jumlah kendaraan yang melintasi jalan yang akan dicari tingat kemacetannya. Pada penelitian ini dipilih jalan urban di kota Palermo. Sebagai pembanding model matematika untuk kemacetan, digunakan model Greenshield, Greenberg, Underwood, Drake, dan Drew. Dari ke 5 model tersebut kemudian dibandingkan model yang mana yang mampu mempresentasikan kondisi lalu lintas di kota Palermo. Penelitian lain tentang simulasi lalu lintas oleh Yastica (2014),dalam penelitiannya dilakukan di Persimpangan Condongcatur DIY, yang bertujuan untuk mengurangi kemacetan di sekitar persimpangan tersebut. Data yang digunakan yaitu data kedatangan kendaraan untuk masing-masing pendekat dan data kecepatan rata-rata kendaraan. Verifikasi model dalam penelitian ini dilakukan dengan mengecek syntax dan visual testing, sedangkan validasi dilakukan dengan uji chisquare.Hasil simulasi yang diperoleh adalah rata-rata waktu tunggu dari kendaraan di setiap pendekat. Hasil itulah yang kemudian dijadikan penilaian dalam menentukan durasi lampu lalu lintas. Kemudian dalam penelitian ini, pembangkitan skenario baru dilakukan untuk mendapatkan pengaturan durasi lampu lalu lintas yang lebih baik dengan mengubah durasi lampu hjau dari setiap pendekat. Setelah itu, skenario yang rata-rata waktu tunggunya lebih rendah dari skenario lainnya akan dipilih sebagai alternatif pengaturan waktu siklus lampu lalu lintas pada Persimpangan Condongcatur.

Berdasarkan tinjauan pustaka yang telah dilakukan, penelitian terkait terhadap kemacetan lalu lintas yang sering dirasakan setiap hari adalah penting dilakukan agar ditemukan solusi seperti apa yang bisa diterapkan oleh pihak Dinas Perhubungan selanjutnya. Penelitian ini berfokus pada persimpangan jalan Kentungan dengan menerapkan jalan underpass serta pengaruh terhadap persimpangan lainnya. Tujuan dari penelitian ini yaitu untuk mengetahui dampak perubahan penurunan tingkat kemacetan yang terjadi dari penerapan jalan underpass tersebut.

2. MetodologiPenelitian

2.1. Tinjauanpustaka

Tinjauan pustaka dilakukan untuk melakukan kajian terhadap penelitianpenelitian sebelumnya sebagai gambaran awal penelitian yang akan dilakukan. Beberapa hal yang ditemukan dalam peninjauan pustaka antara lain yaitu untuk mengetahui kelebihan dan kekurangan dari penelitian terkait yang telah dilakukan serta mengetahui metode yang digunakan.

2.2 Pengumpulan Data

2.2.1 Data yang dibutuhkan

Data yang dibutuhkan dibedakan menjadi dua jenis, yaitu data primer yang didapat dari observasi dengan melakukan pengamatan melalui CCTV. Data yang diobservasi yaitu jumlah kendaraan yang melintasi Persimpangan Kentungan, Condong Catur, dan Palagan.

\subsubsection{Data Primer}

Jumlah kendaraan yang melintasi 3 persimpangan Kentungan, Condong Catur, dan Palagan pada jam sibuk pagi dan sore hari selama satu jam. Pada pengamatan dilakukan pengelompokkan jenis kendaraan berdasarkan dimensi mobil dengan asumsi sebagai berikut:Small car $\leq 4 \mathrm{~m}$ (Jazz, Ayla, Agya, Ertiga, dan sejenisnya), Medium car $\leq 4,4 \mathrm{~m}$ (Avanza, Rush, Xenia dan sejenisnya), Large Car $\leq 5,4 \mathrm{~m}$ (Fortuner, Pajero, Alpard, Hilux, dan sejenisnya), Small Truck $\leq 7 \mathrm{~m}$ (Truk Colt Diesel Double Bak, dan sejenisnya), Medium Truck $\leq 9 \mathrm{~m}$ (Truk Fuso dan sejenisnya) dan Large Truck $\leq 12 \mathrm{~m}$ (Truk kontainer, Tronton dan Bus Pariwisata).

\subsection{InstrumenPenelitian}

Menggunakan Counter untuk menghitung kendaraan yang melintasi Persimpangan, Stopwatch untuk menghitung waktu tunggu kendaraan dan durasi lampu lalu lintas pada setiap pendekat,Google Earth untuk mengukur jarak pelebaran jalan yang belok kiri, Minitab 16 untuk menguji normalitas data, Software Autodesk Infraworks 360 untuk membuat skenario model. 


\subsection{Pengolahan Data}

\subsubsection{UjiKeseragaman Data}

Tahap ini dilakukan untuk mendukung validasi data yang akan digunakan sebagai input simulasi. Tahap ini berfungsi juga sebagai pengendali data yang diluar kendali (out of control). Data yang diuji adalah total kendaraan yang melintasi persimpangan dalam satu jam. Uji keseragaman data ini terdiri dari perhitungan rata-rata, standar deviasi, Upper Control Limit (UCL), Central Line (CL), dan Lower Control Limit (LCL)

\subsubsection{Uji Kecukupan Data}

Setelah melakukan uji keseragaman data, kemudian dilakukan uji kecukupan data yang berfungsi mendukung validasi data yang akan digunakan sebagai input simulasi.

\subsubsection{Pembuatan Model Existing}

Tahap ini dilakukan setelah data dinyatakan seragam dan cukup. Pembuatan model existing ini berdasarkan kondisi saat ini atau sebelum diberi underpass. Pembuatan model ini dengan bantuan software Autodesk Infraworks 360.

2.4.4 Simulasi Model Existing

Tahap selanjutnya yaitu melakukan simulasi model existing. Pada simulasi ini akan diperoleh panjang antrian maksimum dan rata-rata waktu tundaan dari setiap pendekat.

\subsubsection{Verifikasi Model}

Pada tahapan ini dilakukan untuk mengetahui apakah model simulasi yang telah dibuat telah merepresentasikan model konseptual atau berjalan dengan benar sesuai dengan yang diharapkan.

\subsubsection{Validasi Model}

Pada tahapa ini model yang telah dibangun, kemudian di validasi kembali kebenaran dan akurasinya.

\subsection{Analisis data}

\subsection{IAnalisa Validasi model}

Untuk membandingkan dua data dependen pada kondisi yang berbeda. Data yang akan dijadikan validasi adalah panjang antrian maksimum, rata-rata waktu tunggu kendaraan dan rata-rata jumlah kendaraan yang melewati lampu hijau.

2.5.2 Analisis Perbandingan Model Existing dan Skenario
Setelah data dinyatakan valid, kemudian dilakukan perbandingan hasil simulasi khususnya panjang antrian maksimum dan rata-rata waktu tundaan dari masing-masing skenarionya.

\section{Analisa Hasil}

Pada tahap ini dilakukan analisa pada penerapan jalan underpass yang mana dapat menurunkan kemacetan yang signifikan terhadap persimpangan lainnya. Tahap ini merupakan jawaban atas tujuan penelitian dan tahap akhir dari metode penelitian. 


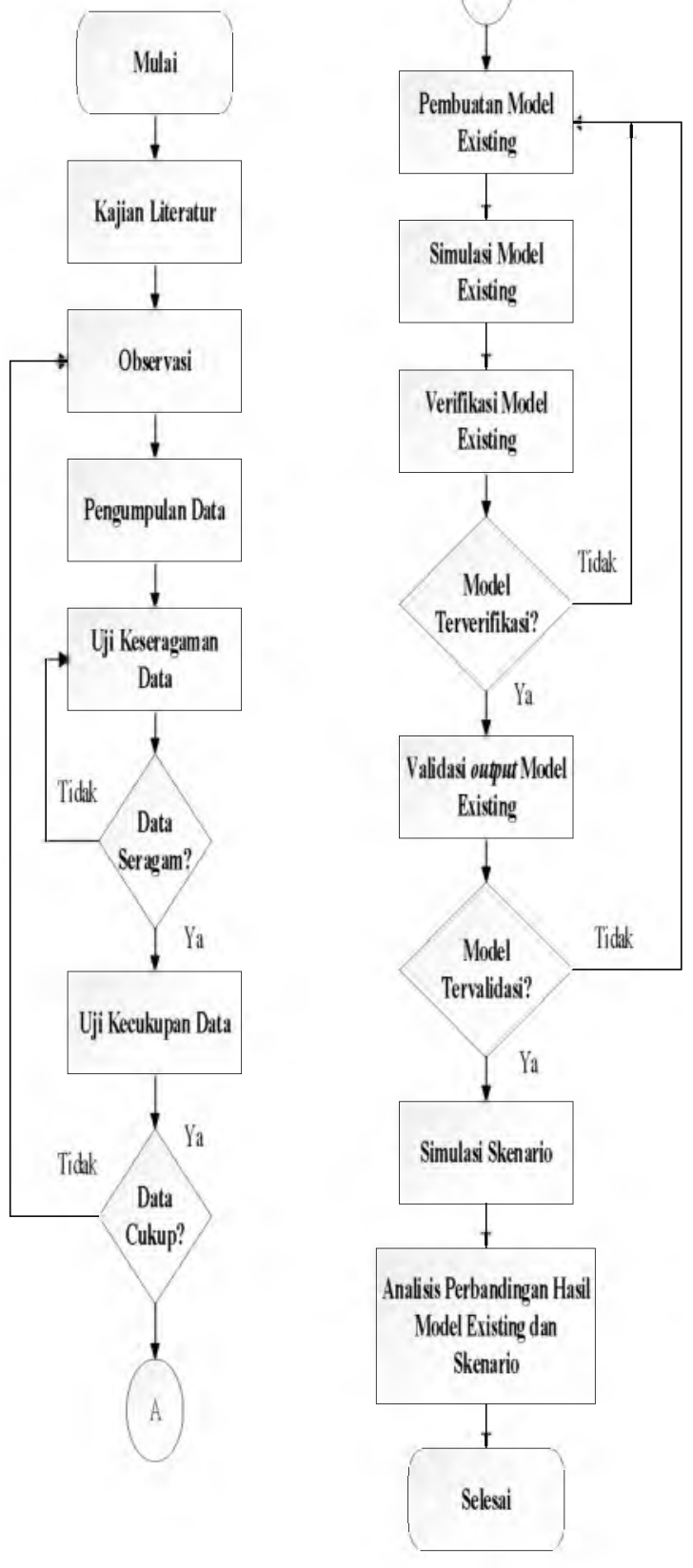

Gambar 2 Flowchart Metodologi Penelitian

4. Kesimpulan

Setelah menerapkan metode kajian literature diatas untuk menemukan solusi terhadap tingkat kemacetan dan waktu tunggu lalu lintas. Diharapkan nantinya dengan menggunakan metode simulasi lalu lintas ini akan bisa ditemukan solusi yang dapat menjawab permasalahan kemacetan yang dihadapi sehari-hari pada jam sibuk. Pada skenario yang akan dibuat bisa memberi masukan ke pada pihak dinas perhubungan terkait, sehingga bias dijadikan pedoman untuk membuat sebuah kebijakan oleh pemerintah atau pun peraturan penjualan kendaraan bermotor yang ada di kota Yogyakarta khususnya untuk dapat membuat langkah pencegahan guna mengurangi kepadatan lalu lintas dan juga bisa memaksimalkan penggunaan kendaraan umum seperti trans jogja maupun transportasi umum lainnya.

\section{DAFTARPUSTAKA}

[1] Banks, J., Carson, J.S., Nelson, B, L., dan Nicol, D, M., 2000, Discrete Event System Simulation, $3^{\text {rd }}$ ed., Prentice Hall Inc, New Jersey.

[2] Dinas Perhubungan DIY, 2016, Studi Evaluasi Kinerja Ruas Jalan dan Simpang Perkotaan, Pemerintah Daerah Istimewa Yogyakarta, Yogyakarta.

[3] Digital Globe, 2017, Letak Persimpangan Kentungan, https://www.google.com.br/maps/ (Online accessed: 20 November 2017.

[4] Direktorat Jenderal Bina Marga dan Pembinaan Jalan Kota, 1990, Panduan Penentuan Klasifikasi Fungsi Jalan di Wilayah Perkotaan, No. 010/T/BNKT/1990.

[5] Kamrani, M., Abadi, S.M.H.E., Golroudbary, R., 2014, Traffic Simulation of Two Adjacent Unsignalized T-Junctions During Rush Hours Using Arena Software, Simulation Modelling Practice and Theorry, Vol.49, pp. 167-179.

[6] Law A.M., dan Kelton W.D., 1991, Simulation Modelling and Analysis, 2nd ed., McGraw-Hill, New York.

[7] Peraturan Menteri Perhubungan Republik Indonesia Nomor PM 111 Tahun 2015, Tata Cara Penetapan Batas Kecepatan, Jakarta.

[8] MKJI, 1997, Manual Kapasitas Jalan Indonesia (MKJI), Direktorat Jenderal Bina Marga Direktorat Bina Jalan Kota, Jakarta.

[9] Salvo, G., Caruso, L., dan Scordo, A., 2014, Urban traffic analysis through an UAV, EWGT2013 - 16th Meeting 
of the EURO Working Group on Transportation, Elsevier.

[10] Shen, Z., Wang, K., dan Zhu, F., 2011, Agent-based Traffic Simulations and Traffic Signal Timing Optimization with GPU, Intelligent Transportation Systems, Vol. 14, pp. 145-150.

[11] Sunartono, 2017, Underpass Kentungan dan Gejayan.http://www.harianjogja.com/ baca/2017/03/14/underpass-

kentungan-gejayan-dampak-sosialdapat-ditekan-ini-penyebabnya$\underline{801000}$ (Online accessed: 15 April 2017).

[12] Yastica, V,T., 2014, Analisis Waktu Siklus Lampu Lalu Lintas dengan Pemodelan Berbasis Agen, Skripsi, Program Studi Teknik Industri Universitas Gadjah Mada, Yogyakarta. 